\title{
Cardiac surgery combined with bypass from the ascending aorta to the bilateral femoral arteries for severe aorto-iliac occlusion: A case series
}

\author{
Côme Bosse, MD, ${ }^{a}$ Ramzi Ramadan, MD, ${ }^{a}$ Dominique Fabre, MD, PhD, ${ }^{\mathrm{b}}$ and Julien Guihaire, MD, PhD, ${ }^{\mathrm{a}}$ \\ Le Plessis Robinson, France
}

\author{
From the Departments of ${ }^{\mathrm{a} C a r d i a c}$ surgery and ${ }^{\mathrm{b}}$ Thoracic and Vascular Surgery and Heart-Lung Transplantation, \\ Marie Lannelongue Hospital and University Paris-Sud, Le Plessis Robinson, France. \\ Disclosures: Authors have nothing to disclose with regard to commercial support. \\ Received for publication Sept 13, 2017; revisions received Nov 16, 2017; accepted for publication Nov 24, 2017; \\ available ahead of print Jan 10, 2018. \\ Address for reprints: Julien Guihaire, MD, PhD, Department of Cardiac Surgery, Marie Lannelongue Hospital, \\ 133 Avenue de la Résistance, 92350 Le Plessis Robinson, France (E-mail: j.guihaire@ccml.fr). \\ J Thorac Cardiovasc Surg 2018;155:1574-7 \\ $0022-5223 / \$ 36.00$ \\ Copyright (c) 2017 by The American Association for Thoracic Surgery \\ https://doi.org/10.1016/j.jtcvs.2017.11.084
}

$\checkmark$ Video clip is available online.

The treatment of choice for symptomatic aorto-iliac occlusion is a prosthetic aorto-bifemoral bypass, which provides excellent long-term results. ${ }^{1}$ However, a subset of patients are not eligible for this procedure, such as those with multiple previous laparotomies, ascites, digestive stomas, or a history of aortic surgery. When endovascular procedures are not possible, an extra-anatomic axillo-bifemoral bypass is feasible, with few perioperative complications but with a 5 -year patency less than $50 \% .^{2}$ Therefore, it cannot be considered for patients with life expectancy greater than 5 years.

The ascending aorta has been reported to provide very good inflow for bypasses ${ }^{3}$ but requires a median sternotomy. This approach is particularly interesting in polyatherosclerotic patients with concomitant coronary artery disease or brachiocephalic trunk (BCT) stenosis requiring surgical revascularization. ${ }^{4}$

The postoperative outcomes of concomitant cardiac surgery and bypass from the ascending aorta to the femoral arteries have been poorly investigated. The purpose of this article is to report our recent experience of cardiac surgery combined with ascending aorta to bifemoral artery bypass, also known as "ventral aorta."

\section{MATERIAL AND METHODS}

We included all consecutive patients who underwent a ventral aorta combined with cardiac surgery in our hospital between 2010 and 2016 . The indication for lower limb revascularization was based on clinical symptoms, assessed by Leriche classification, preoperative angiogram

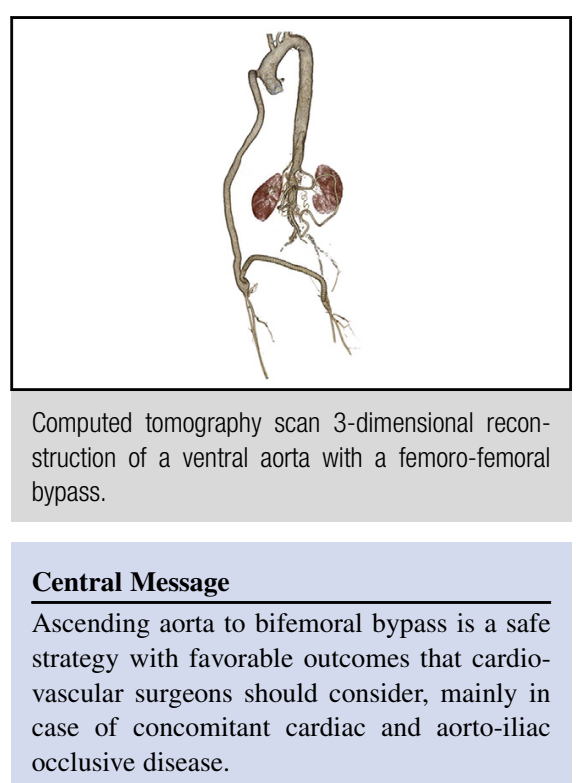

See Editorial Commentary page 1578.

(Figure 1), and Doppler ultrasonography. This indication was extended to paucisymptomatic patients with severe aortoiliac lesions at high risk of postoperative ischemia after cardiac surgery. Exercise challenges were not performed because of cardiac pathologies.

The patient was placed in a supine position. First, the ascending aorta was approached through median sternotomy, and the femoral arteries were dissected after longitudinal groin incisions. A prosthetic conduit (Dacron or polytetrafluoroethylene, diameter 8-16 mm) was tunneled from the mediastinum toward the groin using a smoothended tunnelizer. The graft was introduced behind the rectus abdominus muscle but above the posterior rectus fascia to stay in the preperitoneal layer. An intermediate small incision was performed on the lateral abdominal wall to ensure the correct way of the conduit outside the peritoneum to the inguinal region. The graft was then tunneled toward the groin, going above the inguinal ligament to the femoral artery. After systemic heparinization, cardiopulmonary bypass was established between the ascending aorta and the right atrium, allowing for the cardiac surgery procedure. After weaning from cardiopulmonary bypass, the prosthetic conduit was first sutured to the ascending aorta using a partial lateral aortic clamp (Figure 2, A). The conduit was then sutured to both common femoral arteries, using a Y-shaped bifemoral graft or a right femoral graft associated with cross-femoral bypass (Figure 2, B). In our experience, we used a 10 - $\mathrm{mm}$ ringed polytetrafluoroethylene graft to the most symptomatic limb and made a $\mathrm{Y}$ bifurcation with an $8-\mathrm{mm}$ prosthesis to the contralateral limb. However, the diameter of the femoral arteries was always considered to choose the appropriate size of the distal conduit (Video 1). 


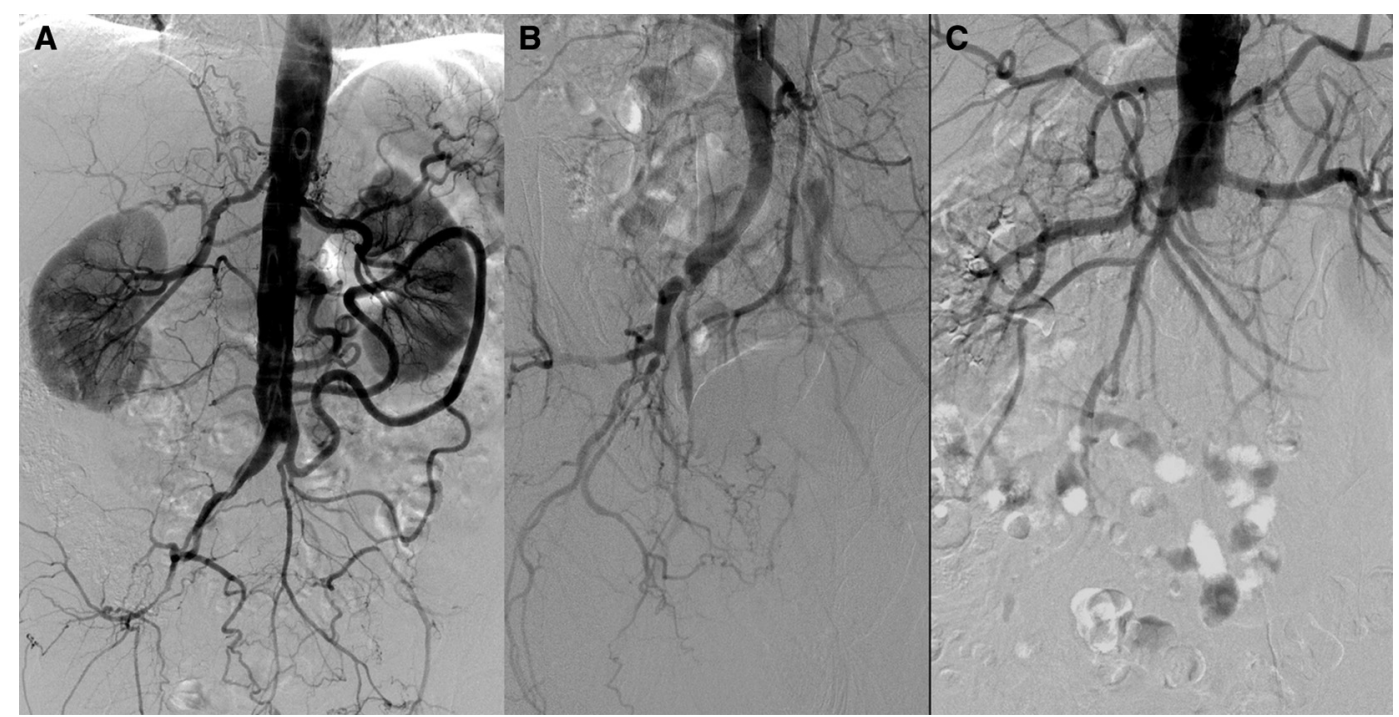

FIGURE 1. Preoperative angiograms. A, Patient number 2 with left common iliac artery and left external iliac artery occlusion, right common iliac artery stenosis, and right external iliac artery occlusion. B, Patient number 4 with left common iliac artery intrastent total occlusion, left external iliac artery occlusion, right common iliac artery stenosis, and right external iliac artery occlusion. C, Patient number 6 with chronic occlusion of the aorta and the common iliac arteries.

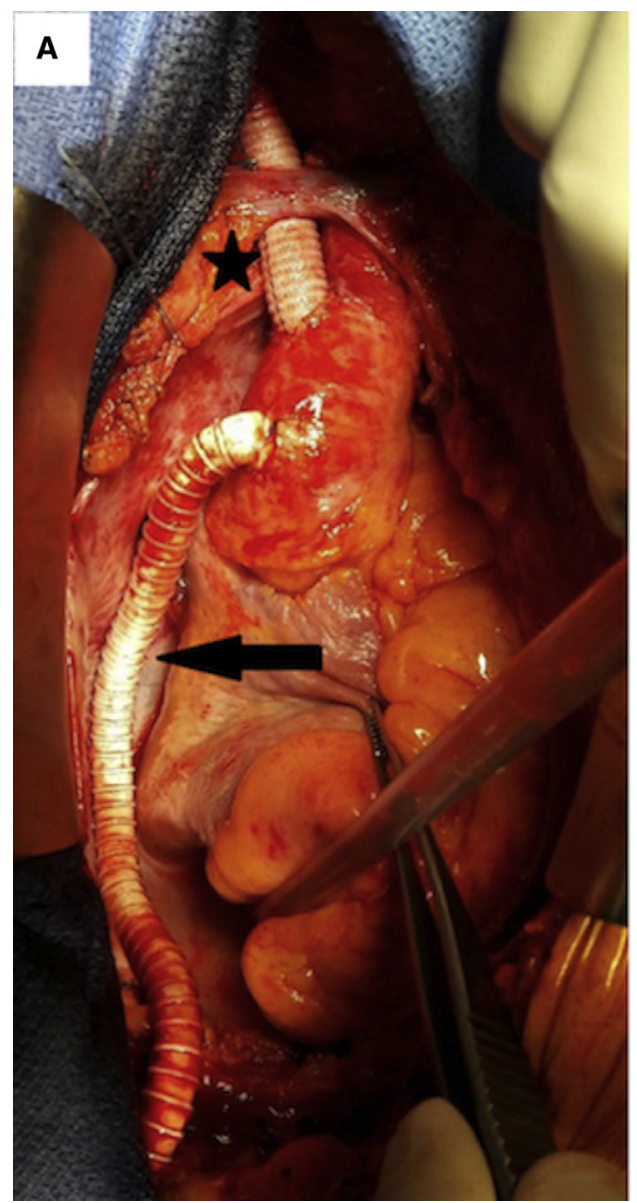

B

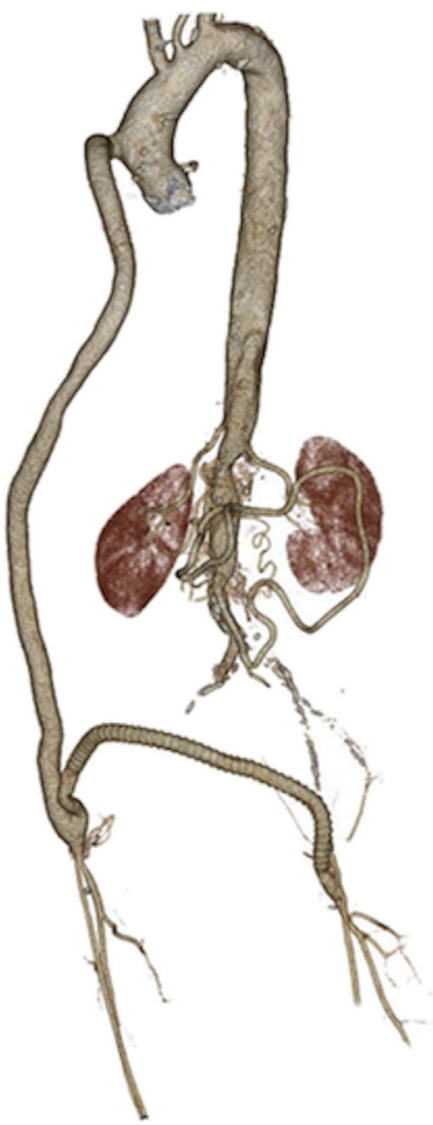

FIGURE 2. A, Perioperative picture of a ventral aorta through sternotomy. The star shows the BCT bypass. The arrow shows the proximal segment of the ventral aorta heading to the femoral arteries. B, Computed tomography scan 3-dimensional reconstruction of a ventral aorta with a femoro-femoral bypass. 


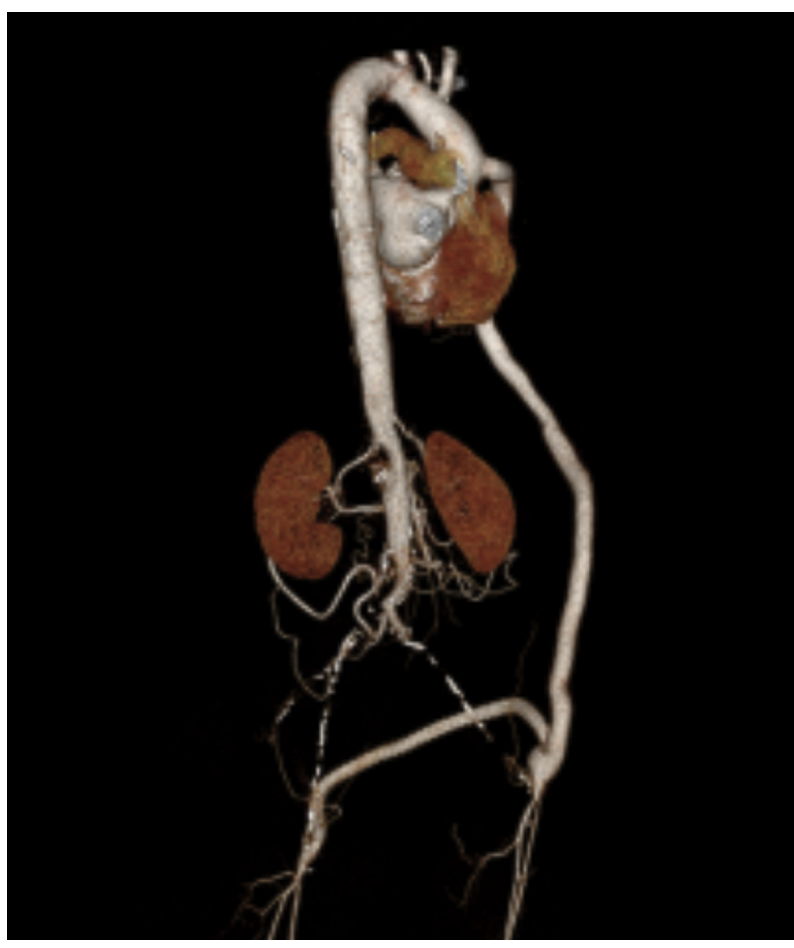

VIDEO 1. Computed tomography scan 3-dimensional reconstruction of a ventral aorta with a femoro-femoral bypass. Video available at: http:// www.jtcvsonline.org/article/S0022-5223(17)32844-1/fulltext.

The demographic data were retrospectively collected. Our local institutional review board approved the study design and waived the need for informed consent. All patients received lifelong antiplatelet therapy with aspirin $75 \mathrm{mg}$ per day, and 1 patient received additional clopidogrel $75 \mathrm{mg}$ for severe coronary disease. Likewise, other cardiovascular risk factors were detected and treated. Long-term graft patency was investigated by repeated physical examination and CT angiogram.

\section{RESULTS}

The preoperative characteristics are listed in Table 1. Six patients required coronary artery bypass grafting
(CABG), 1 patient required BCT bypass for occlusion (Figure 2, A), and 1 patient underwent aortic valve replacement. No perioperative deaths or major complications related to the prosthetic ventral aorta occurred. Three patients had early lymphorrhea of the groin for 6 to 7 days with sterile cultures. It was controlled by standard dressings. The average hospital length of stay was 11 days (4-19). The postoperative results are summarized in Table 2. At 1-month follow-up, all patients had Leriche classification of 0 or 1 . Average follow-up was 25 months (1-66) with a median of 11.3 months. Overall survival at 5 years was $100 \%$. The distal graft patency was $86 \%$ at 5 years because 1 left branch was occluded by a thrombus 9 months after surgery. One patient received downstream surgery, including femoral tripod endarterectomy, 4 years after surgery for symptomatic claudication.

\section{DISCUSSION}

We report the outcomes of combined cardiac surgery (CABG, BCT bypass, or aortic valve replacement) and lower limb revascularization using the "ventral aorta" approach for symptomatic aorto-iliac occlusions. The decision to not perform a conventional aorto-bifemoral bypass was considered in these patients because of inaccessible aorta due to repeated abdominal surgeries or an unclampable aorta due to extended circular calcifications, or after failure of previous aortic surgery. Likewise, percutaneous revascularization was not considered in the setting of chronic and highly calcified lesions of the aorto-iliac bifurcation.

Combined surgery, including CABG and abdominal aortic surgery, has been associated with a major morbidity with approximately $60 \%$ intra-hospital morbi-mortality. Sternotomy is usually known to be associated with transient impairment of respiratory function. By avoiding additional laparotomy, this extraperitoneal procedure does not increase

TABLE 1. Patient characteristics

\begin{tabular}{lclllccccc}
\hline Patient & Male gender & Age, $\mathbf{y}$ & Smoker & HBP & Diabetes & Dyslipidemia & BMI, $\mathbf{k g} / \mathbf{m}^{\mathbf{2}}$ & LVEF $<\mathbf{5 0} \%$ & Cardiac surgery \\
\hline 1 & 1 & 65 & Past & 1 & 1 & 1 & 26 & 0 & CABG \\
2 & 1 & 70 & Active & 1 & 0 & 0 & 24 & 0 & CABG \\
3 & 1 & 65 & Past & 1 & 0 & 0 & 30 & 0 & AVR \\
\hline 4 & 1 & 59 & Active & 1 & 1 & 0 & 24 & 0 & CABG \\
\hline 5 & 0 & 68 & Active & 1 & 0 & 1 & 23 & 0 & CABG \\
\hline 6 & 1 & 75 & Past & 1 & 1 & 0 & 21 & 0 & CABG \\
\hline 7 & 1 & 47 & Active & 0 & 1 & 1 & 30 & 1 & BCT bypass \\
8 & 1 & 51 & Active & 0 & 0 & 1 & 25 & 0 & CABG \\
\hline Average & $87 \%$ & 62.5 & $100 \%$ & $75 \%$ & $50 \%$ & $50 \%$ & 25.4 & $13 \%$ & \\
\hline
\end{tabular}

$H B P$, High blood pressure; $B M I$, body mass index; $L V E F$, left ventricular ejection fraction; $C A B G$, coronary artery bypass grafting; $A V R$, aortic valve replacement; $B C T$, brachiocephalic trunk. 
TABLE 2. Preoperative vascular characteristics

\begin{tabular}{|c|c|c|c|c|c|}
\hline Patient & Rutherford status & Aorto-iliac lesions & TASC II & Critical limb ischemia & Vascular history \\
\hline 1 & 2 & $\begin{array}{l}\text { Aortic stenosis, LCIA severe stenosis, bilateral EIA } \\
\text { stenosis }\end{array}$ & $\mathrm{C}$ & 0 & \\
\hline 2 & 3 & $\begin{array}{l}\text { LCIA and LEIA occlusion, RCIA stenosis, REIA } \\
\text { occlusion }\end{array}$ & $\mathrm{D}$ & 0 & \\
\hline 3 & 3 & $\begin{array}{l}\text { Abdominal aorta and CIA occlusion, REIA and } \\
\text { LEIA stenosis }\end{array}$ & $\mathrm{D}$ & 0 & Iliac endografts \\
\hline 4 & 3 & Aortic, LCIA, RCIA, LEIA, REIA stenosis & $\mathrm{D}$ & 0 & Iliac endografts \\
\hline 5 & 4 & $\begin{array}{l}\text { Aortic stenosis, LCIA and LEIA occlusion, RCIA } \\
\text { and REIA stenosis }\end{array}$ & $\mathrm{D}$ & 1 & \\
\hline 6 & 3 & Aortic occlusion, RCIA and LCIA occlusion & $\mathrm{D}$ & 0 & \\
\hline 7 & 1 & Aortic occlusion, RCIA and LCIA stenosis & $\mathrm{D}$ & 0 & \\
\hline 8 & 3 & $\begin{array}{l}\text { LCIA occlusion, LEIA stenosis REIA stenosis, REIA } \\
\text { occlusion }\end{array}$ & $\mathrm{D}$ & 0 & \\
\hline Average & 3 & & & $13 \%$ & \\
\hline
\end{tabular}

TASC, TransAtlantic Inter-Society Consensus; LCIA, left common iliac artery; EIA, external iliac artery; LEIA, left external iliac artery; RCIA, right common iliac artery; REIA, right external iliac artery; $C I A$, common iliac artery.

the risk of postoperative lung injury. It also provides better inflow compared with standard axillo-bifemoral bypass.

To the best of our knowledge, no recent report has described this combined surgical approach. The absence of major postoperative complications and long-term patency in our experience illustrates the feasibility and the benefits of this combined strategy. The technique is reproducible and has full technical success.

The main limits of this technique are the risk of cerebral embolism in case of balloon thrombectomy, the risk of graft injury in case of future laparotomy, and the theoretic risk of infections because chest and groins are open simultaneously. The present retrospective study is restricted by the small number of patients and the short follow-up for 3 of these patients, which is less than 1 year.

\section{CONCLUSIONS}

In patients with concomitant cardiac disease and chronic aorto-iliac occlusion, ascending aorta to bifemoral bypass combined with cardiac surgery is a safe strategy providing favorable outcomes.

\section{References}

1. Dimick JB, Cowan JA Jr, Henke PK, Wainess RM, Posner S, Stanley JC, et al. Hospital volume-related differences in aorto-bifemoral bypass operative mortality in the United States. J Vasc Surg. 2003;37:970-5.

2. Nguyen KP, Perrone KH, Rahman A, Azarbal AF, Liem TK, Mitchell EL, et al The role of axillofemoral bypass in current vascular surgery practice. Am J Surg. 2016;211:968-71.

3. Baird RJ, Ropchan GV, Oates TK, Weisel RD, Provan JL. Ascending aorta to bifemoral bypass-a ventral aorta. J Vasc Surg. 1986;3:405-10.

4. DeBakey ME, Lawrie GM. Combined coronary artery and peripheral vascular disease: recognition and treatment. J Vasc Surg. 1984;1:605-7.

5. Autschbach R, Falk V, Walther T, Vettelschoss M, Diegeler A, Dalichau H, et al. Simultaneous coronary bypass and abdominal aortic surgery in patients with severe coronary disease-indication and results. Eur J Cardiothorac Surg. 1995;9:678-84. 